\title{
Effects of Particle Collision Treatments on Fatigue Strength of Ti-6Al-4V Alloy with Polishing Marks*1
}

\author{
Tatsuro Morita ${ }^{1, * 2}$, Atsushi Miyatani ${ }^{2, * 3}$, Shogo Takesue ${ }^{1, * 2}$, Masao Kumagai ${ }^{3}$ and Jun Komotori ${ }^{4}$ \\ ${ }^{1}$ Department of Mechanical Engineering, Kyoto Institute of Technology, Kyoto 606-8585, Japan \\ ${ }^{2}$ Department of Mechanical and System Engineering, Graduate School of Science and Technology, Kyoto Institute of Technology, \\ Kyoto 606-8585, Japan \\ ${ }^{3}$ Fuji WPC Co., Ltd., Sagamihara 252-0331, Japan \\ ${ }^{4}$ Department of Mechanical Engineering, Keio University, Yokohama 223-8522, Japan
}

\begin{abstract}
In this study, we attempted to nullify the harmful influences of processing marks on the fatigue strength of Ti-6Al-4V alloy by particle collision treatments. As the surface treatments, fine particle bombarding (FPB) and shot peening (SP) were applied to form hardened layers and introduce compressive residual stress. The surface of the objective material was polished to a mirror surface to eliminate the influences of machining on specimens and was then grinded with emery papers (\#80) to make uniform processing marks. After the particle collision treatments, the surface conditions, hardness distributions and residual stress were systematically examined, and their relationships with the fatigue strength were considered in detail. On observation of the surfaces, the processing marks were eliminated by the particle collision treatments. At the same time, the surface hardness was increased and high compressive residual stress was introduced. As a result, the fatigue strength was markedly improved by the treatments beyond the level of the material with the processing marks without deterioration of the mechanical properties. The improvement rates of the fatigue strength were high, at $75 \%$ by FPB treatment and $58 \%$ by SP treatment. [doi:10.2320/matertrans.MT-Z2021004]
\end{abstract}

(Received April 23, 2021; Accepted June 2, 2021; Published July 9, 2021)

Keywords: fine particle bombarding, shot peening, Ti-6Al-4V alloy, fatigue strength, polishing mark, maximum height waviness, hardness, residual stress, mechanical properties

\section{Introduction}

Ti-6Al- $4 \mathrm{~V}$ is a typical $\alpha+\beta$ titanium alloy that exhibits high specific strength (tensile strength/density) and corrosion resistance. This titanium alloy is widely utilized in aerospace and medical implant fields. The effectiveness is reflected by the proportion of the $\mathrm{Ti}-6 \mathrm{Al}-4 \mathrm{~V}$ alloy, i.e., more than $50 \%$ in the US market, including primarily the abovementioned industries. ${ }^{1)}$ However, the fatigue properties of various titanium materials, including the $\mathrm{Ti}-6 \mathrm{Al}-4 \mathrm{~V}$ alloy, must be considered to guarantee the safety of products fabricated from them.

The work hardening coefficient of titanium is significantly lower than those of aluminum and ferrous materials. For instance, the work hardening coefficient of killed steel is 0.238 , whereas that of the Ti- $6 \mathrm{Al}-4 \mathrm{~V}$ alloy is 0.080 , which is approximately one-fourth that of killed steel. ${ }^{2)}$ In addition, thin $\mathrm{TiO}_{2}$ films formed on the surface of titanium are stable and do not develop significantly at room temperature in air. The abovementioned facts imply that plasticity-induced crack closure and oxide-induced crack closure, ${ }^{3)}$ which generate a non-propagating crack, do not occur easily in titanium. In fact, under cyclic stresses, cracks initiated in titanium do not stop and continue to propagate, thereby resulting in fatigue fractures. Consequently, the fatigue strength of titanium is generally dominated by the maximum stress level that does not initiate fatigue cracks. $\left.{ }^{4}\right)$

General machine parts ineluctably possess stress concentration sites owing to shape changes. In titanium parts, these

\footnotetext{
${ }^{* 1}$ This Paper was Originally Published in Japanese in J. Soc. Mater. Sci., Jpn. 69 (2020) 915-920.

${ }^{* 2}$ Corresponding authors, E-mail: morita@kit.ac.jp, stakesue@kit.ac.jp

${ }^{* 3}$ Graduate Student, Kyoto Institute of Technology
}

stress concentration sites promote crack initiation and reduce the fatigue strength. ${ }^{5)}$ In cases where large stress concentration sites arising from their shape do not exist, the fatigue strength of titanium decreases owing to fine flaws and asperities at the surface. As described above, the fatigue properties of titanium differ significantly from those of ferrous materials, which generate non-propagating cracks easily.

From another viewpoint, because the fatigue strength of titanium is dominated by the limit of crack initiation, when the initiation of fatigue crack is suppressed to a higher stress level by surface treatments, harmful effects such as machining marks can be nullified. Studies ${ }^{6-8)}$ have been performed to investigate the effect of shot peening (SP) on the fatigue properties of the Ti-6Al-4V alloy. However, to the best of our knowledge, studies regarding the nullification of machining marks on surfaces have not been performed.

Hence, in this study, we attempted to nullify the harmful effects of stress concentration sites such as fine machining marks on the fatigue strength of the Ti- $6 \mathrm{Al}-4 \mathrm{~V}$ alloy by forming a hardened layer and introducing compressive residual stresses via surface treatments. An alloy with polishing marks generated using emery paper (\#80) after mirror-finishing was used as the treated material. Fine particle bombarding (FPB) and SP were performed using appropriate conditions derived from a previous study. ${ }^{9)}$ The surface morphologies, microstructures, hardness distributions, and residual stresses were analyzed, and their relationships with the mechanical and fatigue properties were analyzed comprehensively. Herein, FPB and SP are collectively referred to as particle collision treatments. 


\section{Experimental Procedures}

\subsection{Materials and treatment conditions}

Table 1 shows the chemical composition of the Ti-6Al-4V alloy used in this study. Rolled bars with a diameter of $10.5 \mathrm{~mm}$ were prepared. Before machining into the specimen, annealing was performed at $1023 \mathrm{~K}$ for $3.6 \mathrm{ks}$ to eliminate residual stresses. This material is referred to as the $\mathrm{AN}$ series.

Table 1 Chemical composition of Ti-6Al-4V alloy (mass\%).

\begin{tabular}{cccccccc}
\hline Al & $\mathrm{V}$ & $\mathrm{Fe}$ & $\mathrm{O}$ & $\mathrm{H}$ & $\mathrm{C}$ & $\mathrm{N}$ & $\mathrm{Ti}$ \\
\hline 6.14 & 4.17 & 0.220 & 0.200 & 0.004 & 0.004 & 0.003 & $\mathrm{Ba}$. \\
\hline
\end{tabular}

The AN series was machined into three types of specimen configurations, as shown in Fig. 1. The button-shaped specimen shown in Fig. 1(a) was used to investigate the surface morphology, microstructure, and hardness distributions. The specimens shown in Figs. 1(b) and (c) were applied to tensile and fatigue tests, respectively. The test sections of each specimen were polished and mirror-finished using emery paper (\#400-\#2500) and a colloidal silica (diameter: $80 \mathrm{~nm}$ ) suspension to eliminate effects from prior machining. Subsequently, polishing marks were induced in the test sections using emery paper (\#80). This specimen is referred to as the \#AN series.

FPB and SP were performed for the \#AN series under the conditions presented in Table 2 at room temperature in air. The applied conditions were demonstrated to be effective for
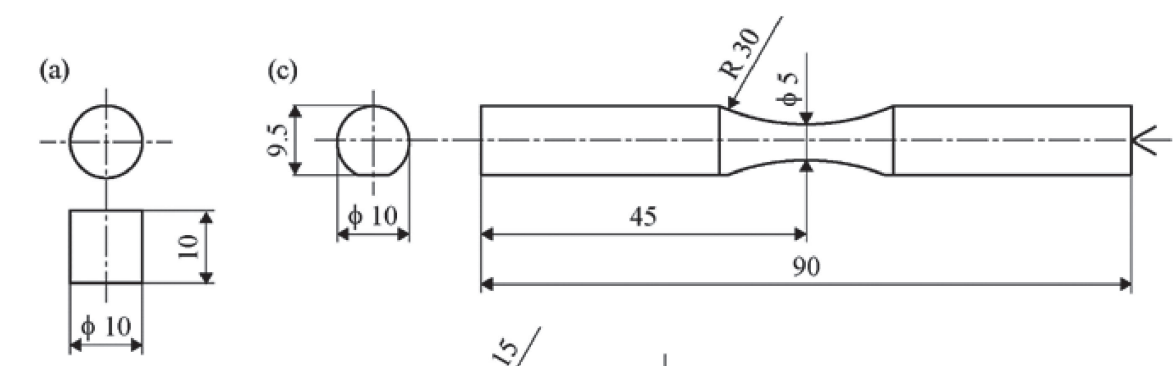

(b)

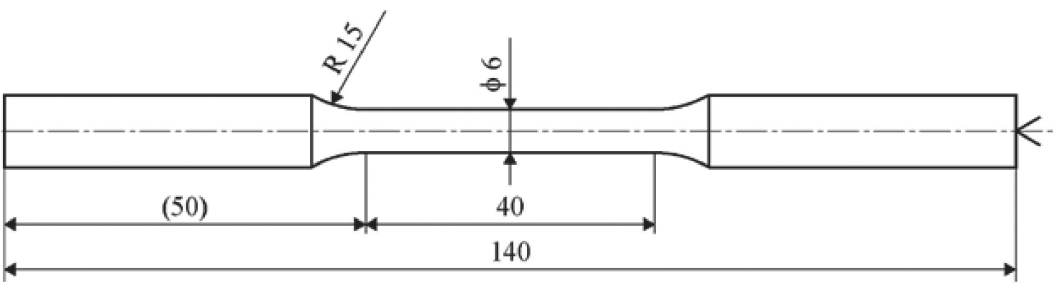

Fig. 1 Configurations of specimens (mm): (a) button shape specimen; (b) tensile specimen (JIS Z 2241, No. 14); (c) fatigue specimen (JIS Z 2274).

Table 2 Treatment conditions of fine particle bombarding and shot peening.

\begin{tabular}{|c|c|c|c|c|c|c|}
\hline \multirow[b]{2}{*}{ Abbreviation } & \multicolumn{3}{|c|}{$1 \mathrm{st}$ treatment } & \multicolumn{3}{|c|}{$2 \mathrm{nd}$ treatment } \\
\hline & $\begin{array}{l}\text { Particle } \\
\text { material }\end{array}$ & $\begin{array}{l}\text { Injection } \\
\text { pressure }\end{array}$ & $\begin{array}{l}\text { Treatment } \\
\text { time }\end{array}$ & $\begin{array}{l}\text { Particle } \\
\text { material }\end{array}$ & $\begin{array}{l}\text { Injection } \\
\text { pressure }\end{array}$ & $\begin{array}{l}\text { Treatment } \\
\text { time }\end{array}$ \\
\hline \# F P B & $\begin{array}{c}\text { High speed } \\
\text { stee } 1 \\
\text { (diameter: } \\
55 \mu \mathrm{m})\end{array}$ & $0.6 \mathrm{MPa} *$ & $\begin{array}{c}\text { Button } \\
\text { specimen: } \\
10 \mathrm{~s}\end{array}$ & $\mathrm{SiO}_{2}$ & & $\begin{array}{c}\text { Button } \\
\text { specimen: } \\
10 \mathrm{~s}\end{array}$ \\
\hline \# S P & $\begin{array}{c}\text { High speed } \\
\text { steel } \\
\text { (diameter: } \\
500 \mu \mathrm{m} \text { ) }\end{array}$ & $0.1 \mathrm{MPa} * *$ & $\begin{array}{c}\text { Tensile } \\
\text { and fatigue } \\
\text { specimens: } \\
30 \mathrm{~s}\end{array}$ & $45 \mu \mathrm{m})$ & & $\begin{array}{c}\text { Tensile } \\
\text { and fatigue } \\
\text { specimen: } \\
30 \mathrm{~s}\end{array}$ \\
\hline
\end{tabular}

*: Gravity suction type,**: Direct pressure type 
improving the fatigue strength of the Ti-6Al-4V alloy in a previous study. ${ }^{9)}$ The FPB and SP treatments comprised two procedures. The former treatment using high-speed steel particles was aimed at forming hardened layers and introducing compressive residual stresses, whereas the latter treatment using $\mathrm{SiO}_{2}$ particles was aimed at reducing the surface roughness. The treatment times were $10 \mathrm{~s}$ for the button-shaped specimen and $30 \mathrm{~s}$ for the tensile and fatigue specimens. These settings were used to provide the same total kinetic energy per unit area at the surfaces of each specimen. ${ }^{10)}$ The \#AN series treated with FPB is referred to as the \#FPB series, whereas that treated with SP is referred to as the \#SP series. The diameter of the abrasive particles of the \#80 emery paper used to induce polishing marks was $150 \mu \mathrm{m}$, which was between the particle diameters used in the first FPB treatment $(55 \mu \mathrm{m})$ and first SP treatment $(500 \mu \mathrm{m})$.

\subsection{Characterization}

The surface morphologies of the specimens were observed using scanning electron microscopy (SEM). The microstructures near the specimen surfaces were analyzed using SEM and electron backscatter diffraction (EBSD) after etching the mirror-finished cross-sections using Kroll's etchant ( $\mathrm{HF}(40 \%) 2 \%, \mathrm{HNO}_{3}$ (1.40) $13 \%, \mathrm{H}_{2} \mathrm{O}$ 85\%). ${ }^{11)}$ During EBSD analyses, image quality (IQ) maps, inverse pole figure (IPF) maps and phase maps were obtained.

The arithmetic average roughness $R_{\mathrm{a}}$ and maximum height waviness $W_{\mathrm{z}}$ of the specimen surfaces were measured using a laser microscope. ${ }^{12}$ ) The cutoff values during the measurements were $\lambda_{\mathrm{s}}=2.5 \mu \mathrm{m}$ and $\lambda_{\mathrm{c}}=80 \mu \mathrm{m} .{ }^{13)} \lambda_{\mathrm{s}}$ is the lower limit of the surface roughness wavelength, and $\lambda_{\mathrm{c}}$ is the threshold value of the wavelength divided by the surface roughness and waviness.

The surface hardness and hardness distributions were measured using a dynamic super microhardness tester because low-force measurements were required. A triangular pyramid diamond indenter was used, and HT115 was measured. The hardness was determined by measuring the size of the triangle indentation and dividing the test force by the surface area of the indentation, which are similar to the Vickers hardness. The test force was $30 \mathrm{mN}$, and the holding time was $15 \mathrm{~s}$. The hardness at each position was determined based on the average of five measurements.

$\mathrm{X}$-ray residual stresses were measured at the center of the test section of the fatigue specimen along the axial direction. The $\sin ^{2} \psi$ method was applied, and peak searches were performed using the half-width center method. The measurement conditions were as follows: X-ray tube, $\mathrm{Cu} \mathrm{K} \alpha$; diffraction plane, (213); diffraction angle $2 \theta, 142.0^{\circ} ; \Psi$ angles, $10^{\circ}, 20^{\circ}, 30^{\circ}, 35^{\circ}$, and $40^{\circ}$; stress constant, $-258.2 \mathrm{MPa} /{ }^{\circ}$.

Tensile tests were performed based on JIS Z 2241 at room temperature in air. Strain was measured using a strain gauge attached to the center of the specimen. The experimental results were determined as the average values of results obtained using the two specimens. Plane bending fatigue tests were performed at room temperature in air. The frequency was $25 \mathrm{~Hz}$, and the stress ratio was -1 . The initiation sites of the fatigue cracks were observed on the fracture surfaces using SEM. The results of the AN series for comparison were obtained from a previous study. ${ }^{9)}$

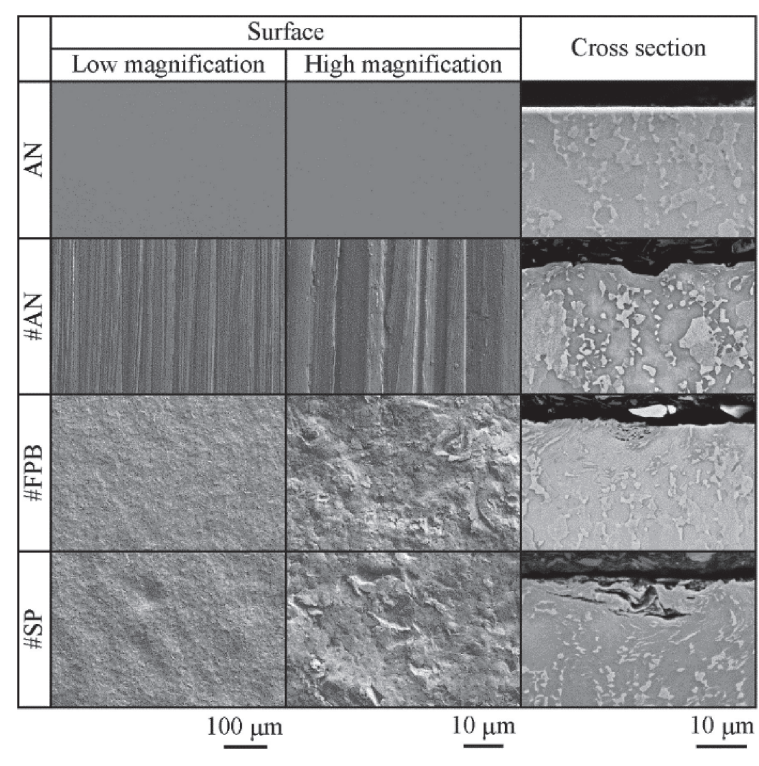

Fig. 2 Features observed on the surfaces and cross sections.

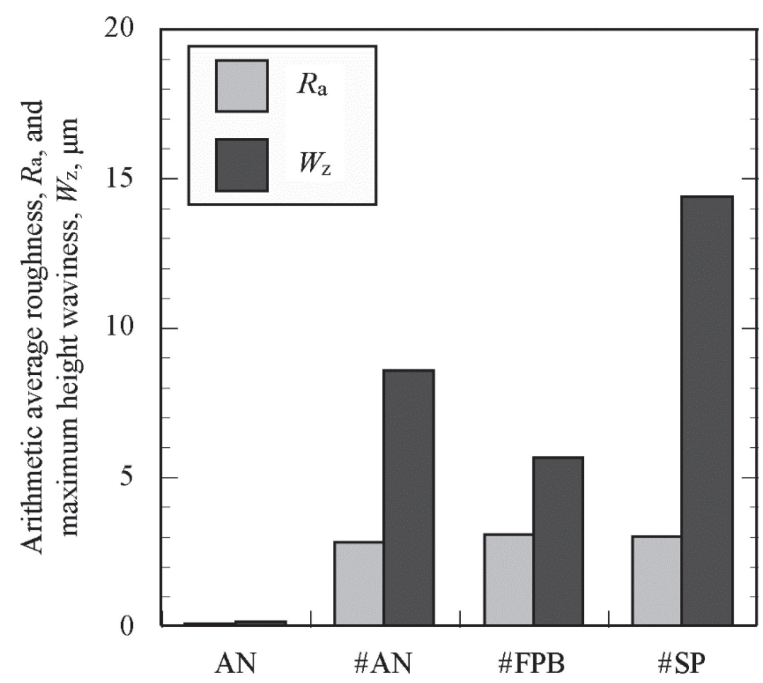

Fig. 3 Arithmetic average roughness and maximum waviness of each material.

\section{Results and Discussion}

\subsection{Surface morphology}

Figure 2 shows micrographs of the surface morphologies and longitudinal sections of each specimen. Figure 3 presents the $R_{\mathrm{a}}$ and $W_{\mathrm{z}}$ measured at the specimen surfaces using a laser microscope.

As shown in Fig. 2, the surface of the AN series was smooth, whereas numerous sharp polishing marks were formed via polishing using emery paper. From cross-sectional observations, machining traces were not recognized near the surface of the AN series, whereas plastic deformation due to polishing by emery paper was observed near the surface of the \#AN series. The $R_{\mathrm{a}}$ and $W_{\mathrm{z}}$ values of the AN series were low, whereas those of the \#AN series were relatively high (Fig. 3), which agreed with the SEM observations.

The sharp polishing marks formed on the surface of the \#AN series completely disappeared after FPB and SP treatments. In addition, plastic flows due to particle collisions 
were observed near the surfaces of the \#FPB and \#SP series as well as on the stratification-patterned layers, ${ }^{14,15)}$ which were created by folding fine protrusions formed by local particle collisions into craters.

Differences in the roughness and waviness between the \#FPB and \#SP series were not clearly reflected from the SEM images owing to the large focus depth of SEM. However, as shown in Fig. 3, the $W_{\mathrm{z}}$ value of the \#FPB series was lower than that of the \#AN series, whereas the value of the \#SP series was higher than that of the \#AN series. This result indicates that the waviness of the treated surface depends on the particle diameter of the high-speed steel used during the first treatment and increases with the particle diameter. The difference in the $R_{\mathrm{a}}$ values between the \#FPB and \#SP series was insignificant. This suggests that the surface roughness depends on the second treatment, in which $\mathrm{SiO}_{2}$ fine particles are used.

As revealed in a previous study, ${ }^{9}$ the fatigue strength of the Ti-6Al-4V alloy does not depend significantly on $R_{\mathrm{a}}$ but on $W_{\mathrm{z}}$. Therefore, the results presented above indicate that FPB is more effective than SP in improving the fatigue strength, even if the \#AN series is targeted. This is explained comprehensively in Section 3.3.

\subsection{Microstructures, hardness distributions, and resid- ual stresses}

Figure 4 shows the results of EBSD analyses (IQ, IPF and phase maps) performed at the cross-sections of the specimens. The results of the AN series revealed that the microstructure of the untreated specimen comprised the equiaxed $\alpha$ phase and fine $\beta$ phase. The black regions observed near the surfaces of the \#AN, \#FPB, and \#SP series were the regions where EBSD data could not be acquired adequately because the dislocation density increased and the crystallinity became disordered owing to polishing using emery paper or particle collisions. In previous studies, ${ }^{14,15)}$ refined grains were assumed to be present in these black regions. The black region formed in the \#SP series was deeper than that formed in the \#FPB series because the kinetic energy per particle was significantly higher in the SP treatment than in the FPB treatment. ${ }^{10)}$

Figure 5 shows the cross-sectional hardness distributions measured from the surface to the interior of each specimen. The hardness measured at the surface was 0 point on the horizontal axis. The \#AN series, which exhibited work hardening during polishing using emery paper, indicated a higher hardness than the AN series near the surface. Highhardness layers were formed at the surfaces of the \#FPB and \#SP series. The layer was thicker in the \#SP series than in the \#FPB series, which is consistent with the EBSD analysis.

However, the hardness distributions within $20 \mu \mathrm{m}$ from the surface did not differ significantly between the specimens. It is inferred that the increasing rate of hardness owing to work hardening decreased as plastic deformation increased; this is because the work hardening coefficient of the Ti-6Al$4 \mathrm{~V}$ alloy is extremely low, as reported in a previous study, $\left.{ }^{9}\right)$ and the surface temperature increased because a higher kinetic energy per unit volume was induced during the FPB treatment, thereby resulting in recovery and dynamic recrystallization.

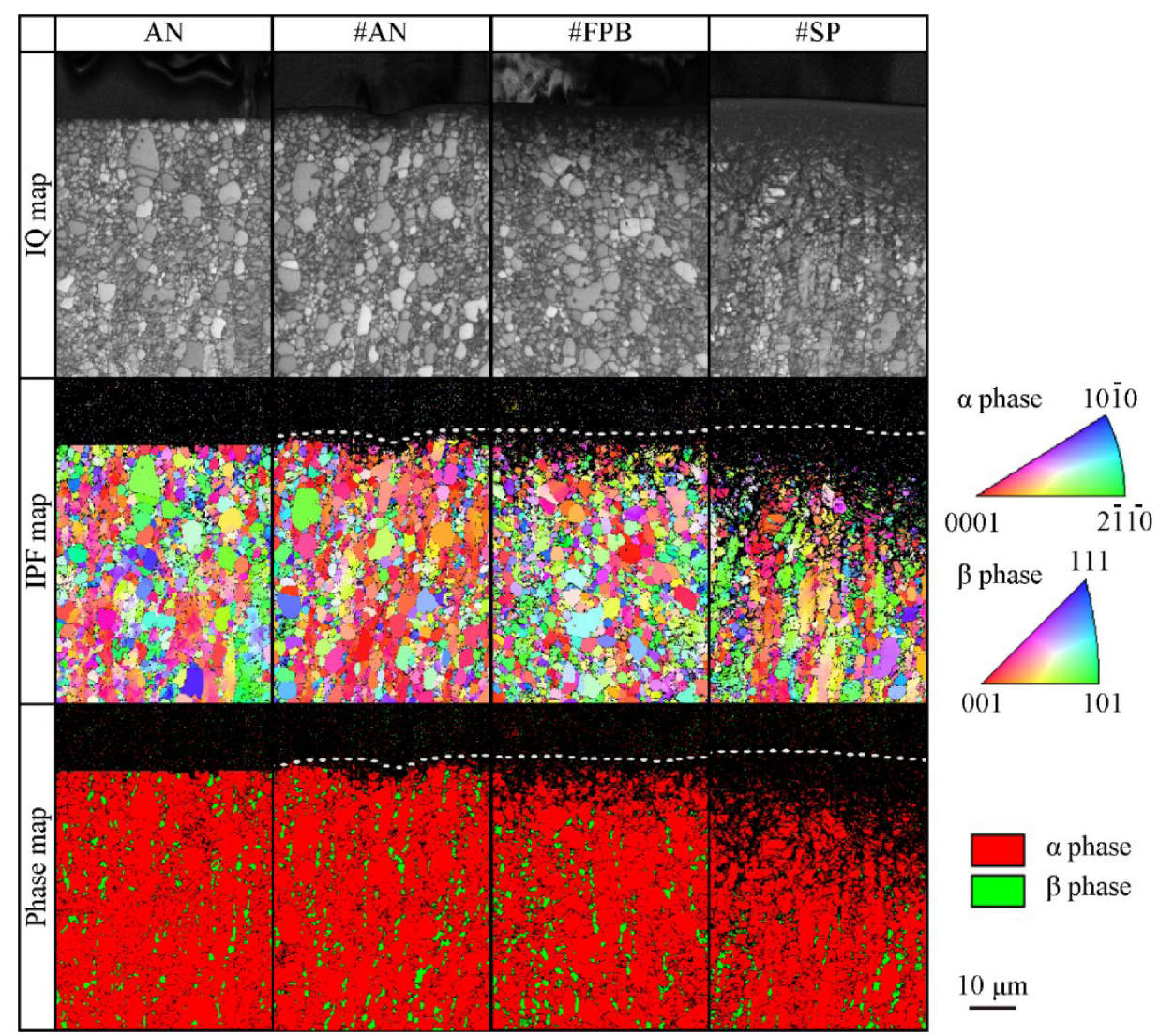

Fig. 4 Results of EBSD analysis conducted near the surfaces on the cross sections. 


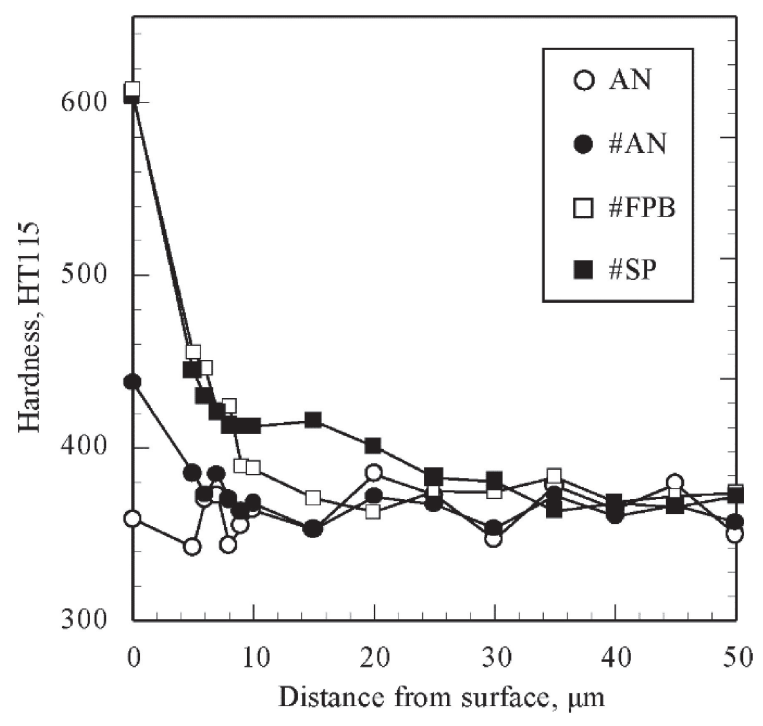

Fig. 5 Hardness distributions.

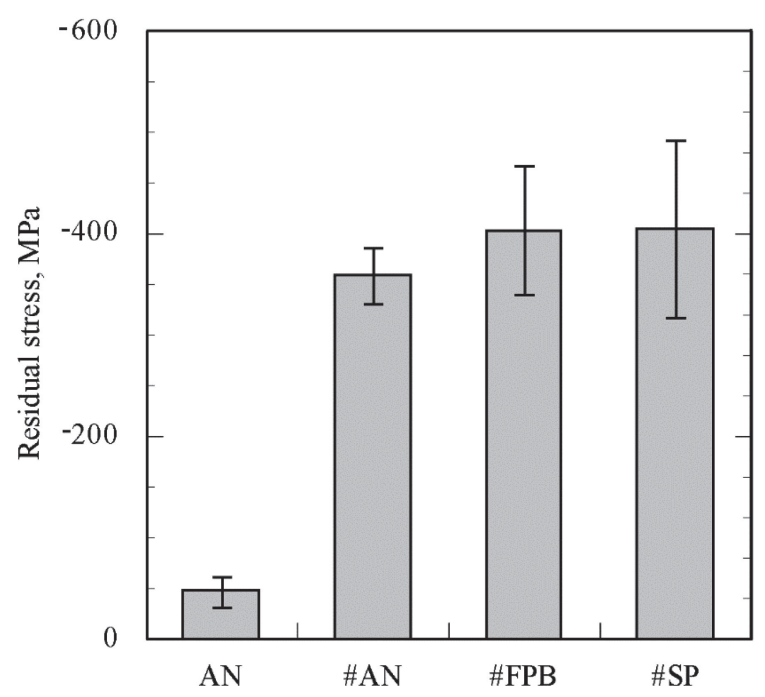

Fig. 6 Residual stress measured on the surfaces.

Figure 6 shows the residual stresses measured at the surfaces of the fatigue specimens along the axial direction. The AN series indicated a low compressive residual stress value (absolute value). By contrast, a relatively high compressive residual stress was generated owing to plastic deformation via polishing using emery paper. Subsequent particle collision treatments increased the compressive residual stress values slightly. However, the difference in compressive residual stress between the \#FPB and \#SP series was small.

\subsection{Mechanical properties and fatigue properties}

Table 3 lists the mechanical properties of the specimens. The effects of polishing by emery paper and particle collision treatments were limited near the surfaces of the specimens, and the inner microstructure was not affected. Therefore, the mechanical properties of all specimens were similar.

Figure 7 shows the S-N curves of the specimens, and Fig. 8 presents the features of the fatigue crack initiation sites observed at the fracture surfaces. As mentioned above, compared with the AN series, in the \#AN series, the surface
Table 3 Mechanical properties.

\begin{tabular}{cccccc}
\hline & Young's & Yield & Tensile & & Reduction \\
modulus & strength & strength & Elongation & $(\%)$ & of area \\
& $(\mathrm{GPa})$ & $(\mathrm{MPa})$ & $(\mathrm{MPa})$ & & $(\%)$ \\
\hline AN & 107 & 983 & 1033 & 14 & 44 \\
\hline \#AN & 114 & 962 & 1025 & 16 & 49 \\
\hline \#FPB & 116 & 961 & 1034 & 16 & 48 \\
\hline \#SP & 119 & 957 & 1039 & 15 & 43 \\
\hline
\end{tabular}

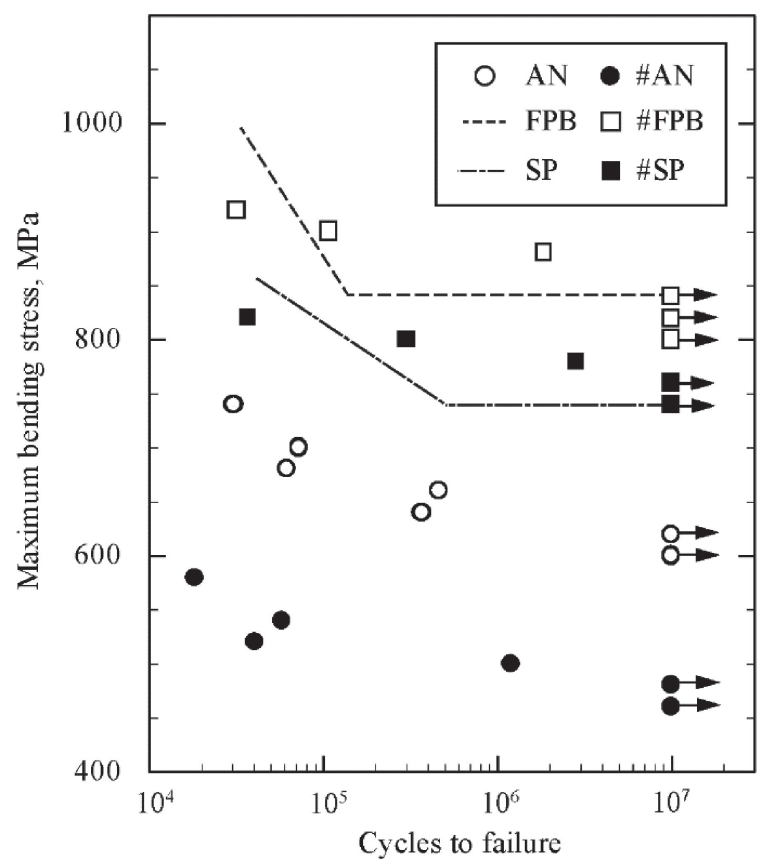

Fig. 7 S-N curves.

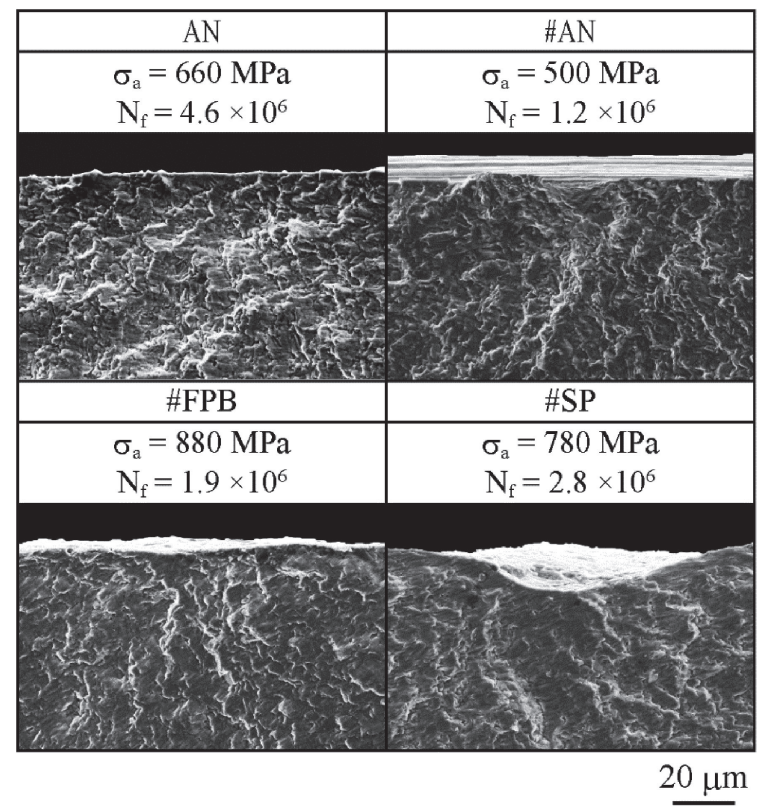

Fig. 8 Features observed near the crack initiation sites on the fracture surfaces. 
hardness increased and a high compressive residual stress was introduced via polishing using emery paper. However, a fatigue crack was initiated from the bottom of the sharp polishing mark in the \#AN series (Fig. 8). As shown in Fig. 7, the fatigue strength of the \#AN series decreased significantly compared with that of the AN series. The fatigue strength of the \#AN series decreased because the harmful effect of stress concentration at the bottom of the sharp polishing mark trumped the improvement effect of the increase in surface hardness and the introduction of compressive residual stresses induced by polishing using emery paper.

By contrast, sharp polishing marks were eliminated by particle collision treatments. Simultaneously, the surface hardness and absolute value of the compressive residual stress increased. Consequently, as revealed in Fig. 7, the fatigue strengths of the \#FPB and \#SP series improved compared with that of the \#AN series, and they exceeded the level of the AN series. The improvement rates of the treated specimens as compared with the \#AN series were $75 \%$ and $58 \%$ for the \#FPB and \#SP series, which were significantly higher.

Although the surface hardness and compressive residual stress values of the \#FPB and \#SP series were similar, the \#FPB series exhibited a higher fatigue strength than the \#SP series. As shown in Fig. 8, fatigue cracks were initiated at the bottom of the waviness with the maximum size in the \#FPB and \#SP series. As mentioned above, the surface hardness and compressive residual stress values of the \#FPB series were the same as those of the \#SP series; therefore, the difference in fatigue strength was attributed to the size of the waviness. Namely, the waviness was small at the FPB-treated surface because the used particle diameter was small, which was more effective for improving the fatigue strength of the Ti-6Al-4V alloy.

In Fig. 7, the lines represent the S-N curves of the FPB and SP series from a previous study, ${ }^{9)}$ where the series were subjected to FPB and SP treatments for the AN series under the same conditions as those used in this study. As shown in this figure, regardless of the surface conditions before the treatments (mirror-finished or polished using emery paper), the respective fatigue strengths after FPB and SP treatments were similar. It is suggested that the surface roughness and waviness introduced by polishing using emery paper in this study can be rendered harmless by FPB or SP treatments, and that significant improvements in fatigue strength can be achieved consequently.

\section{Conclusions}

In this study, the authors attempted to eliminate the harmful effects of stress concentration sites such as fine processing marks at the surfaces on the fatigue strength of the Ti-6Al-4V alloy by forming hardened layers and introducing compressive residual stresses through particle collision treatments. After performing mirror-finishing, polishing marks were introduced onto the treated alloy using emery paper. By performing various systematic experiments, the following conclusions were obtained:

(1) The sharp polishing marks formed at the surface of the \#AN series using emery paper were eliminated completely by FPB or SP treatments. Owing to these treatments, the surface hardness increased, and the compressive residual stress increased slightly. The difference in compressive residual stress values between the \#FPB and \#SP series was insignificant.

(2) Because the effects of polishing using emery paper, FPB treatment, and SP treatment were limited near the surfaces of the specimens, all specimens analyzed in this study exhibited similar mechanical properties.

(3) The fatigue strengths of the \#FPB and \#SP series increased significantly because sharp polishing marks at the surface were eliminated, and surface hardness and compressive residual stress increased. The fatigue strengths of the \#FPB and \#SP series improved by $75 \%$ and $58 \%$, respectively, which were relatively high. FPB, which generated small waviness, was more effective than SP in terms of the improvement in fatigue strength.

(4) The fatigue strengths of the specimens treated with FPB or SP were similar regardless of the surface conditions (mirror-finished or polished using emery paper) prior to the treatments. This indicates that the surface roughness and waviness induced in this study were rendered harmless by particle collision treatments.

\section{REFERENCES}

1) G. Lutjering and J.C. Williams: Titanium, (Springer, Berlin, 2003) p. 7.

2) The Japan Titanium Society: Processing Technology for Titanium, (Nikkan Kogyo Shimbun, Ltd, Tokyo, 2003) p. 69, p. 73.

3) M. Jono and J.H. Son: Fatigue Crack, (Osaka University press, Osaka, 2005) pp. 15-20.

4) K. Takao, M. Sogo and K. Matsumoto: Trans. Jpn. Soc. Mech. Eng. 52 (1986) 2574-2578

5) K. Takao and H. Nishitani: Proc. 2nd Int. Conf. Fatigue Failure Thresholds, 2 (1984) 827-834.

6) Y. Kitsunai, M. Tanaka and E. Yoshihisa: J. Soc. Mater. Sci. Jpn. 43 (1994) 666-671.

7) Y. Kato, S. Takafuji and M. Kiriyama: J. Soc. Mater. Sci. Jpn. 45 (1996) 43-47.

8) K. Masaki, Y. Yonakuni, N. Hisamori, Y. Suga, Y. Kobayashi and D. Gowa: J. Soc. Mater. Sci. Jpn. 65 (2016) 679-686.

9) T. Morita, A. Miyatani, S. Kariya, M. Kumagai, S. Takesue and J. Komotori: Results Mater. 7 (2020) 100128.

10) T. Morita, H. Nakahigashi, S. Noda and C. Kagaya: Mater. Trans. 53 (2012) 1938-1945

11) P. Gunter: Materialkundich-Technische Reile 1: Metallographisches Altzen, translated by G. Matsumura, (Agne Publishing Co., Tokyo, 1982) pp. 95-96.

12) Japanese Industrial Standards: JIS B 0601.

13) I. Yoshida: J. Jpn. Soc. Precis. Eng. 78 (2012) 301-304.

14) T. Morita, S. Noda and C. Kagaya: Mater. Sci. Eng. A 574 (2013) 197204.

15) T. Morita, S. Noda and C. Kagaya: Mater. Trans. 55 (2014) 646-652. 